\title{
Anomalous DnaA protein binding to the regulatory region of the Escherichia coli aldA gene
}

\author{
Toru Ozaki, Yuichi Kumaki,† Risa Kitagawał and Tohru Ogawa
}

Author for correspondence: Tohru Ogawa. Tel: +8152789 2584. Fax: +81527895732. e-mail:h44851a@nucc.cc.nagoya-u.ac.jp

Division of Biological Science, Graduate School of Science, Nagoya University, Chikusa-ku, Nagoya 464-8602, Japan

\begin{abstract}
A binding site for DnaA protein was identified in the regulatory region of the aldA gene of Escherichia coli. Specific binding was demonstrated by in vitro assays including filter binding as well as mobility shift in a polyacrylamide gel of the DnaA-DNA complex. In cells growing in minimal medium containing glucose, expression of $\beta$-galactosidase activity from an aldA-lac $Z$ fusion gene was suppressed by oversupply of DnaA protein and was enhanced by reducing the free DnaA level. These results suggest that DnaA protein negatively regulates expression of the aldA gene under these conditions. Despite fairly strong binding, the bound DNA fragment had no consensus 9 bp DnaA binding sequence (DnaA box), and anomalous binding to an AT-rich sequence located close to the transcription start site was revealed by a footprinting experiment.
\end{abstract}

Keywords: DnaA, aldA, transcription, replication, Escherichia coli

\section{INTRODUCTION}

The DnaA protein of Escherichia coli is the initiator protein of chromosomal replication and binds to the five 9 bp repeats termed DnaA boxes, TTAT(C/A)CA(C/A)A (Fuller et al., 1984) or TT(A/T)TNCACA (Schaper \& Messer, 1995), in the replication origin, oriC. Assisted by protein HU or IHF, cooperative binding of 20-40 monomers of ATP-bound DnaA protein per oriC stimulates duplex opening at the ATrich 13-mer repeats in ori $\mathrm{C}$, where several replication proteins are loaded to initiate DNA replication (Kornberg \& Baker, 1992). Besides being present in oriC, DnaA boxes are found at many sites on the chromosome and some of them located close to promoters of genes are involved in regulation of expression of the genes (Messer \& Weigel, 1997). Binding of DnaA to the promoter region mostly inhibits but in some cases stimulates transcription. In addition, binding of DnaA to some but not all binding sites located within genes terminates transcription (Messer \& Weigel, 1997). DnaA binding to DnaA boxes plays an important role not only in replication initiation and

\footnotetext{
†Present address: INTEC Web and Genome Informatics Corporation, Bio Informatics Group, 1-3-3 Shinsuna, Koto-ku, Tokyo 136-0075, Japan.

$\ddagger$ Present address: Department of Medical Genetics, University of British Columbia, 6174 University Boulevard, Vancouver, BC, Canada V6T 1 Z3.
}

transcription control but also in the timing of initiation of replication. The chromosomal locus $\operatorname{dat} A$, which titrates a large amount of DnaA molecules, has been suggested to exert such a function by regulating the cellular concentration of free DnaA molecules during the cell cycle (Kitagawa et al., 1996, 1998).

There is some uncertainty in predicting DnaA-binding activity from a nucleotide sequence, partly because it seems to be affected by some poorly characterized factor(s). It is known that a 9 bp sequence, which binds DnaA when located in certain surrounding sequences does not bind it in other places (Fuller et al., 1984). In another case, weak binding has been observed of a 368 bp pBR322 fragment, which lacks strong homologies to the DnaA box (Fuller et al., 1984). A relaxed consensus sequence, (T/C) $(\mathrm{T} / \mathrm{C})(\mathrm{A} / \mathrm{T} / \mathrm{C}) \mathrm{T}(\mathrm{A} / \mathrm{C}) \mathrm{C}-$ $(\mathrm{A} / \mathrm{G})(\mathrm{A} / \mathrm{C} / \mathrm{T})(\mathrm{A} / \mathrm{C})$, has been proposed (Schaefer \& Messer, 1991), but it is not clear how many base changes from the original consensus sequence are allowed. It seems, therefore, to be necessary to characterize more actual DnaA-binding sites to establish the sequence features involved in the binding. Such studies would contribute to understanding the role of DnaA protein in the global control of gene expression and the cell cycle.

The ald $A$ gene encodes an aldehyde dehydrogenase of broad substrate specificity (Hidalgo et al., 1991; Limon et al., 1997). The gene is induced by hydroxyaldehydes and 2-oxoglutarate, which are formed as metabolic 
intermediates of various carbohydrates and amino acids (Quintilla et al., 1991). In addition, expression of the gene is activated by Crp-cAMP and is repressed under anaerobic growth conditions by ArcA-P, the phosphorylated response regulator of the ArcB/A two-component signal-transduction system (Pellicer et al., 1999).

In this paper, we report that a DNA segment encompassing the aldA regulatory region has DnaA-binding activity. Despite a fairy strong binding, the region has no canonical DnaA box. A footprinting experiment suggested that DnaA initially interacts with an AT-rich site between the -10 promoter sequence and the transcription start point, leading to cooperative binding to a region of about $100 \mathrm{bp}$ around the site at higher DnaA concentrations.

\section{METHODS}

Bacterial strains and plasmids. E. coli $\mathrm{K}-12$ derivatives used were DH5 $\alpha$ [supE44 $\Delta l a c U 169$ ( $\phi 80$ lacZ $\Delta M 15)$ recA1 endA1 gyrA96 thi-1 relA1] and CSH50 [ara $\Delta$ (lac-pro) strA thi].

Plasmid pRP270T was constructed by inserting a 261 bp TaqI fragment carrying the aldA regulatory region and a part of the coding sequence at the SmaI site of pUC119. pBRP270 was constructed by replacing the small EcoRI-SalI fragment of pBR322 with the EcoRI-SalI fragment of pRP270T, which carries the 261 bp TaqI fragment. pMAPCdSG10 (Fuller et al., 1984) is a pBR322 derivative which has no DnaA boxes downstream of the replication origin. pFPMCLZ1 and pTOA50 have been described (Kitagawa et al., 1996). pFCmLZ1 carries a promoter-less lacZ gene and was constructed by inserting a ScaI-AseI fragment of pMC1871 (Amersham Pharmacia Biotech) into the Bsu36I site of the mini-F plasmid pFCm (Kitagawa et al., 1996). pFAL1 carries the promoter and the $\mathrm{N}$-terminal three codons of the aldA gene fused in-frame to the lacZ gene on pFCmLZ1. This plasmid was made by inserting the EcoRI-FokI fragment of pRP270T into the SmaI site of pFCmLZ1 after treatment with the large fragment of DNA polymerase I. pROA200 (Kitagawa et al., 1996) is a pUC119-based plasmid, which carries the $d n a A$ gene of E. coli under control of the tac promoter in addition to the lacl $^{\mathrm{q}}$ gene. pROA199 was derived from pROA200 by removing an EcoRI fragment which contains the dnaA gene. pROAKK-EX (Kitagawa et al., 1996) carries the chromosomal $\operatorname{dat} A$ region on the pACYC177-based vector pROAKK1.

Filter binding assay. Preparation of DnaA protein has been described (Kitagawa et al., 1996). pRP270T was cleaved with $\mathrm{XbaI}$ and $\mathrm{SacI}$ to separate the insert fragment from the vector portion. The digest was labelled with $\left[\alpha^{32} \mathrm{P}\right] \mathrm{dCTP}$ using the large fragment of DNA polymerase I. pMAPCdSG10 was linearized with $X b a I$, labelled similarly and used as a negative control. Mixtures of these three DNA fragments $(0.26 \mathrm{nM}$ each, $1 \cdot 23-2.25 \times 10^{3}$ c.p.m. fmol ${ }^{-1}$ ) were subjected to the binding reactions with DnaA protein as described by Fuller et al. (1984), except that ATP $(1 \mu \mathrm{M})$ and sonicated salmon sperm DNA $(0.5 \mu \mathrm{g}$ per $25 \mu \mathrm{l})$ were present in the reaction mixtures. Bound DNA fragments were eluted and analysed as described by Fuller et al. (1984), except that radioimages were obtained and radioactive bands was quantified by a BAS 1000 Bio Imaging Analyzer (Fuji Photo Film).

Gel mobility shift assay. The DNA fragments analysed were the 282 bp XbaI-SacI fragments of pRP270T carrying the aldA regulatory region and labelled at the $5^{\prime}$ ends of the $\mathrm{XbaI}$ site using $\left[\gamma_{-}{ }^{32} \mathrm{P}\right]$ ATP and polynucleotide kinase. Labelled fragments (2500 c.p.m. per $10 \mathrm{fmol}$ ) were mixed with various amounts of DnaA in $6 \mu$ reaction mixtures containing $25 \mathrm{mM}$ HEPES/KOH (pH 8.0), $6 \mathrm{mM}$ magnesium acetate, $0.8 \mathrm{mM}$ EDTA, $4 \mathrm{mM}$ dithiothreitol, $0.01 \%$ Triton X-100, $80 \mu \mathrm{g}$ bovine serum albumin $\mathrm{ml}^{-1}, 80 \mu \mathrm{M}$ ATP, $80 \mu \mathrm{g}$ E. coli tRNA $\mathrm{ml}^{-1}$ and $7 \%(\mathrm{v} / \mathrm{v})$ glycerol. After incubation for $5 \mathrm{~min}$ at $20{ }^{\circ} \mathrm{C}$, mixtures were subjected to $4 \%(\mathrm{w} / \mathrm{v})$ polyacrylamide gel electrophoresis (acrylamide:bisacrylamide, 29:1) in $10 \mathrm{mM}$ Tris/borate (pH 8.3), $0.2 \mathrm{mM}$ EDTA. The gel was dried on a DE81 paper (Whatman) and autoradiographed. E. coli tRNA was used as a competitor to reduce nonspecific DNA binding; we found that it works similarly to the sonicated salmon sperm DNA used in the filter binding assay.

DNase I footprinting. The DNA fragments used were prepared from pRP270T. Radioactive label was introduced after $\mathrm{XbaI}$ treatment, either at the $3^{\prime}$ end using $\left[\alpha^{32} \mathrm{P}\right] \mathrm{dCTP}$ and the large fragment of DNA polymerase $\mathrm{I}$, or at the $5^{\prime}$ end using $\left[\gamma-{ }^{32} \mathrm{P}\right] \mathrm{ATP}$ and polynucleotide kinase. Labelled DNA was treated with TaqI and the $288 \mathrm{bp}$ fragment containing the ald $A$ regulatory region was purified by agarose gel electrophoresis. End-labelled fragments $\left(1-3.5 \times 10^{5}\right.$ c.p.m. per $60-80$ fmol) were combined with DnaA buffer or with 100-250 ng DnaA protein in five tubes containing $12 \mu \mathrm{l}$ solutions for the gel mobility shift assay described above. After electrophoresis and autoradiography, seven bands corresponding to the bands 0-6 in Fig. 2 were excised from the gel and treated in gel slices with DNase I under conditions which permit partial hydrolysis (Straney et al., 1989). DNA fragments were eluted from gel slices, subjected to polyacrylamide gel electrophoresis under denaturing conditions, and radioimages were obtained using a BAS 1000 Bio Imaging Analyzer.

Assay of $\boldsymbol{\beta}$-galactosidase. Plasmid-carrying cells of CSH50 were grown at $30^{\circ} \mathrm{C}$ to exponential phase in M9 glucose medium supplemented with $40 \mu \mathrm{g} \mathrm{L-proline} \mathrm{ml}^{-1}$ and $5 \mu \mathrm{g}$ thiamin $\mathrm{ml}^{-1}$ and appropriate antibiotics $(30 \mu \mathrm{g}$ ampicillin $\mathrm{ml}^{-1}, 10 \mu \mathrm{g}$ chloramphenicol $\mathrm{ml}^{-1}$ ). IPTG was added where indicated at $0.5 \mathrm{mM}$ and cells were harvested $6 \mathrm{~h}$ after addition of the inducer. The $\beta$-galactosidase activity was assayed as described by Miller (1972). Assays were performed six to nine times with at least three independent cultures.

\section{RESULTS}

\section{Binding of DnaA to the aldA regulatory region}

In surveying an aligned E. coli DNA library (Kohara et al., 1987) by filter binding assays (Fuller $e$ t al., 1984), we found that clone 270 has a fairly strong DnaA-binding activity. The binding activity of this clone (containing 16635 bp E. coli DNA sequence) was localized to a $261 \mathrm{bp}$ TaqI fragment, which carries the regulatory region of the aldA gene. This fragment was subcloned into the SmaI site of pUC119 (plasmid pRP270T).

In the experiment shown in Fig. 1, various amounts of DnaA protein were added to reaction mixtures containing three labelled linear DNA fragments: vector pUC119, the insert fragment containing the aldA regulatory region, and pMAPCdSG10. The DnaA-DNA complexes formed were collected on nitrocellulose filters and the bound DNA fragments were recovered and 
(a)

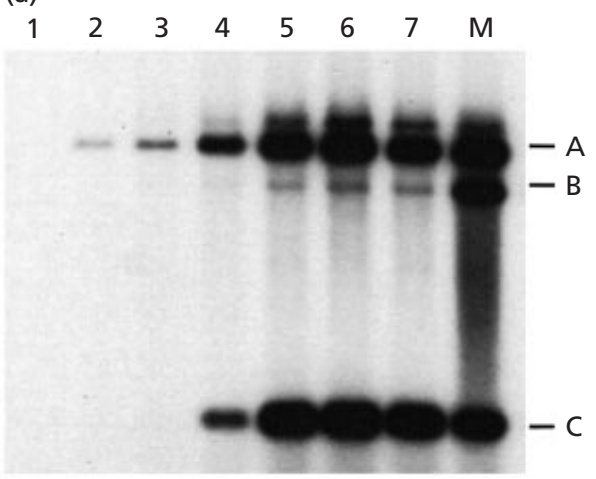

(b)

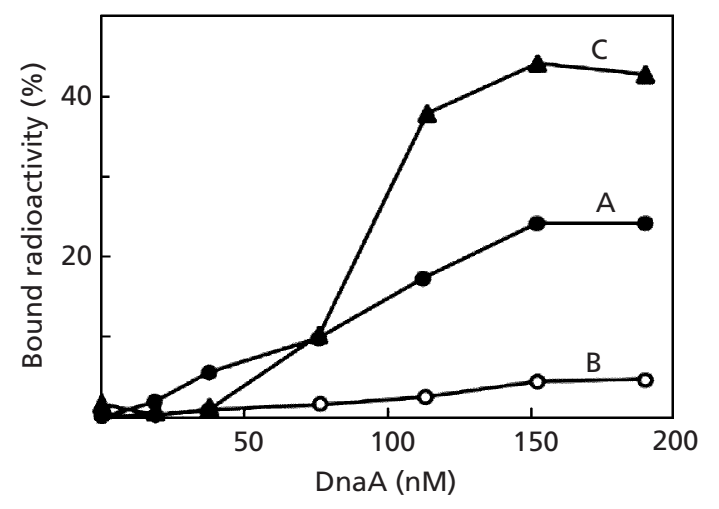

Fig. 1. Agarose gel electrophoresis of DNA bound to DnaA protein. (a) A filter binding assay was carried out with three labelled DNA fragments as described in Methods. DNA fragments retained on the filter were eluted and analysed. Concentrations of DnaA $(\mathrm{nM})$ in reaction mixtures for lanes 1-7 were $0,19,38,76,114,152$ and 190, respectively. In lane M, a portion of the DNA fragment mixture used in the assay was directly loaded on the gel. Positions of the vector DNA (A), linear pMAPCdSG10 DNA (B) and the insert fragment carrying the aldA regulatory region (C) are indicated on the right. (b) Radioactive bands in (a) were quantified and plotted versus DnaA concentration. The ordinate represents the proportion of bound radioactivity in each DNA fragment.

analysed by agarose gel electrophoresis. pUC119 has two DnaA boxes downstream of the replication origin, which enhance plasmid replication by functioning as a loading site of primosomal proteins for synthesis of the lagging strand (Parada \& Marians, 1991). pMAPCdSG10, on the other hand, has no DnaA box.

From the figure, it is evident that DnaA protein bound the insert fragment. The binding was more efficient than that to the vector DNA, especially at higher DnaA concentrations. As expected, pMAPCdSG10 did not bind DnaA.

From a similar assay in the absence of the competitor, the dissociation constant $\left(K_{\mathrm{d}}\right)$ of the $261 \mathrm{bp}$ TaqI fragment was estimated to be $1 \cdot 3 \pm 0 \cdot 2 \times 10^{-8} \mathrm{M}$ (data not shown). This value is only $1 \cdot 5$-fold higher than the $K_{\mathrm{d}}$ for an oriC fragment measured in a similar ex-

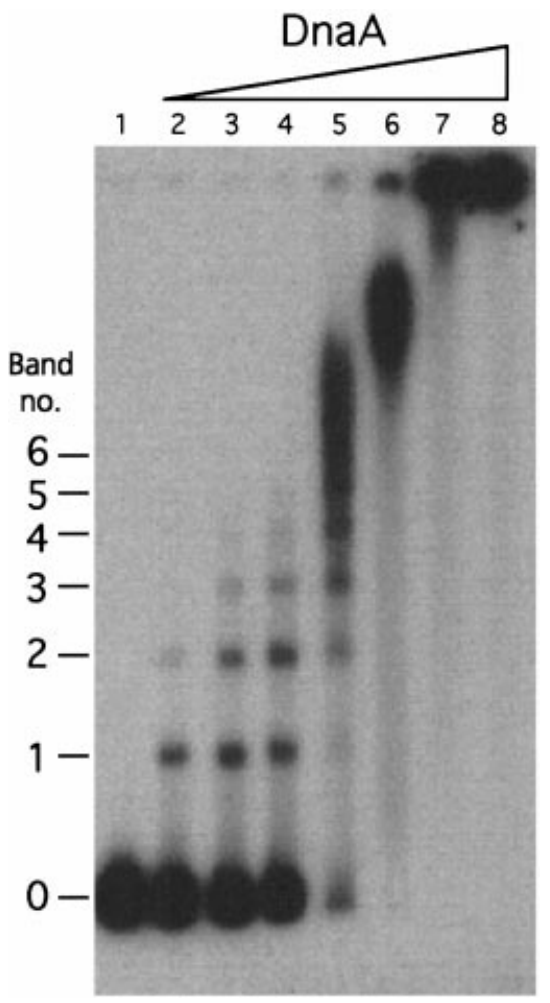

Fig. 2. Gel mobility shift assay of DnaA complexed to the aldA regulatory region. Amounts of DnaA protein added were 0,10 , $20,30,40,50,75$ and $100 \mathrm{ng}$ in lanes $1-8$, respectively. Band 0 corresponds to free DNA fragment.

periment (Kitagawa et al., 1996) and it indicates that the affinity of DnaA to the TaqI fragment is fairly strong.

Specific binding of DnaA to the aldA regulatory region was analysed by a gel mobility shift assay with purified DNA fragment and DnaA protein (Fig. 2). Discrete bands were resolved in the gel and slowly migrating species increased at higher DnaA protein concentrations. Shift to larger complexes occurred continuously until all DNA molecules stayed at the origin, although resolution of bands was incomplete in the upper part of the gel. These results suggest that a specific complex is formed first and then progressively converted to more complicated structures by cooperative binding of additional DnaA molecules.

\section{Characterization of the binding site by a foootprinting experiment}

Despite the clear binding, the $261 \mathrm{bp}$ TaqI fragment has no canonical $9 \mathrm{bp}$ DnaA box sequence. In order to identify the interaction sites, DNase I footprinting was performed (Fig. 3). End-labelled fragments complexed with DnaA protein were first separated by nondenaturing polyacrylamide gel electrophoresis. Free DNA band and six shifted bands, 1-6, corresponding to those in Fig. 2 were partially hydrolysed in gel slices with 
upper strand

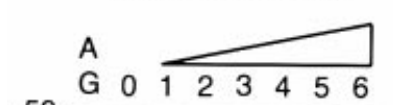

$-40$

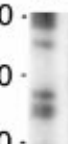

123456

20

60

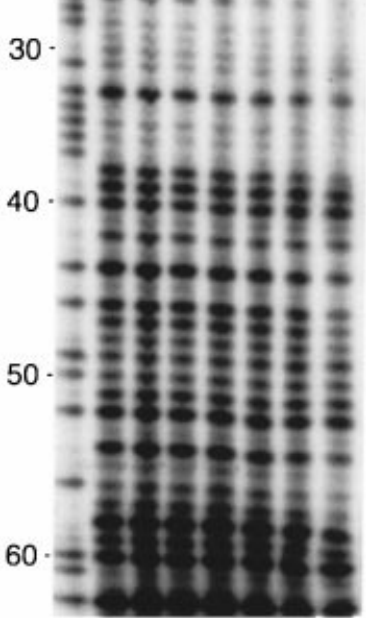

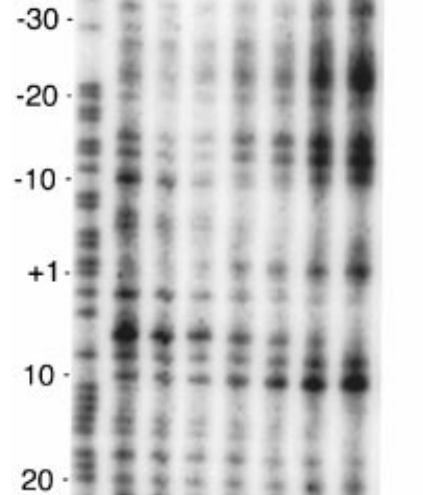

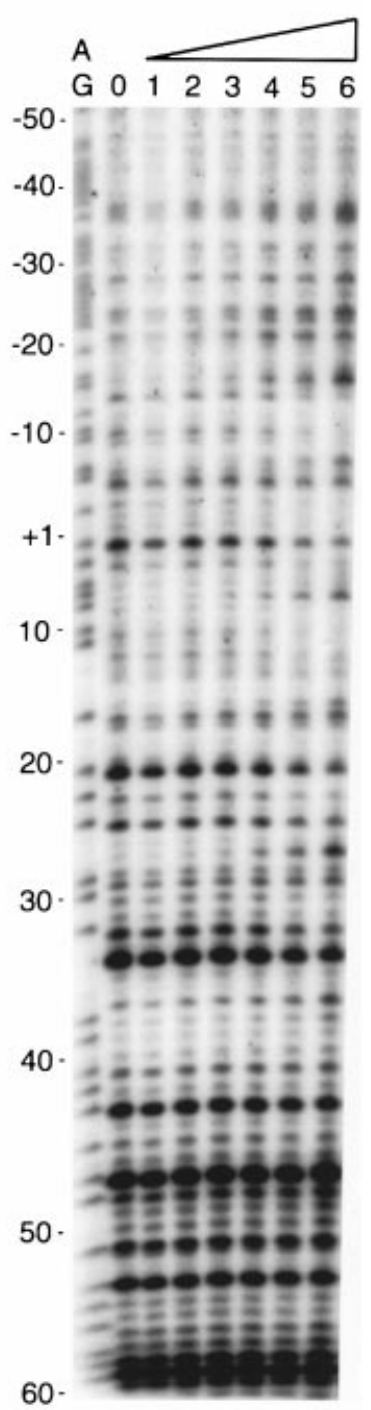

lower strand

Fig. 3. Footprint of $D n a A$ protein bound to the aldA gene regulatory region. Upper and lower strands denote the representation in Fig. 4. The fragment used was the Taql-Xbal fragment of pRP270T labelled at the $3^{\prime}$ end of the Xbal site (upper strand) or at the $5^{\prime}$ end of the Xbal site (lower strand). In lanes 0-6, radioactive bands corresponding to bands 0-6 in Fig. 2 were analysed. Triangles at the top indicate increase of the bound DnaA protein. The leftmost lanes are ladders of the Maxam-Gilbert $A+G$ reaction. Numbers on the left are the nucleotide coordinates, with the transcription start site being +1 .

DNase I and subjected to polyacrylamide gel electrophoresis under denaturing conditions. The results are schematically summarized in Fig. 4.

Protection from the nuclease digestion first occurred at a site between the transcription start site and the -10 sequence (Pribnow Box) on the upper strand. Upon increase of the number of bound molecules, the protected region extended in both directions accom- panied by periodic enhanced cleavage sites. Both protection and enhancement sites repeated at roughly $10 \mathrm{bp}$ intervals and finally covered about $100 \mathrm{bp}$ of sequence. Far upstream, at least beyond the XmnI site at position -58 , seemed to have no effect on DnaA binding (data not shown).

It was difficult to find a distinct protection site that appeared in response to the band shift from band 2 and after. Rather, several bands seemed to diminish simultaneously and gradually upon the mobility shift to slower bands. This may suggest that ordered DnaA binding to fixed sites is not involved in the formation of complexes in bands 2-6.

\section{Binding of DnaA to the aldA regulatory region in vivo}

The region bound by DnaA overlapped with the regulatory region of the aldA gene. This gene encodes NAD-linked aldehyde dehydrogenase with a broad substrate spectrum and is under control of several transcriptional regulators that bind to sites within or near the region bound by DnaA (Limon et al., 1997; Pellicer et al., 1999) (Fig. 4). Therefore, we next examined whether DnaA binds to this region as well in vivo, using a system to measure the level of derepression of a mioC-lac $Z$ fusion gene upon introduction of a plasmid carrying the aldA regulatory region. The miniF-based plasmid pFPMCLZ1 has the promoter region and a portion of the coding sequence of the mioC gene fused in-frame to the lac $Z$ gene. The fusion gene is negatively controlled by DnaA by its binding to the DnaA box at the promoter region, and therefore a change in cellular DnaA level can be detected by measuring the $\beta$-galactosidase activity (Hansen et al., 1987; Kitagawa et al., 1996). Presence of a DnaAbinding sequence in the same cell on a compatible plasmid should result in a derepression of the fusion gene.

The activity of $\beta$-galactosidase in a lacZ strain (CSH50) carrying pFPMCLZ1 and the vector plasmid pBR322 was $0.52 \pm 0.05 \mathrm{U}$. On the other hand, the activity was increased to $1.56 \pm 0.08 \mathrm{U}$ in the strain carrying pFPMCLZ1 and pBRP270, which has the $261 \mathrm{bp}$ TaqI fragment. This value was higher than the $\beta$-galactosidase activity in cells carrying pFPMCLZ1 and pTOA50, which is a chimeric plasmid of oriC and pBR322 $(1 \cdot 14 \pm 0 \cdot 18 \mathrm{U})$. It should be noted that the copy number of pTOA50 is 1.5-2-fold higher than that of pBRP270 (data not shown). These results suggest that the aldA regulatory region can titrate more DnaA molecules than oriC in vivo.

\section{Negative control of aldA gene expression by DnaA}

In order to examine the role of DnaA in aldA gene expression, the regulatory region and $\mathrm{N}$-terminal three codons of the gene $(-184$ to 52$)$ was fused in-frame to the lac $Z$ gene on a mini-F plasmid. Activity of $\beta$ - 
(a)
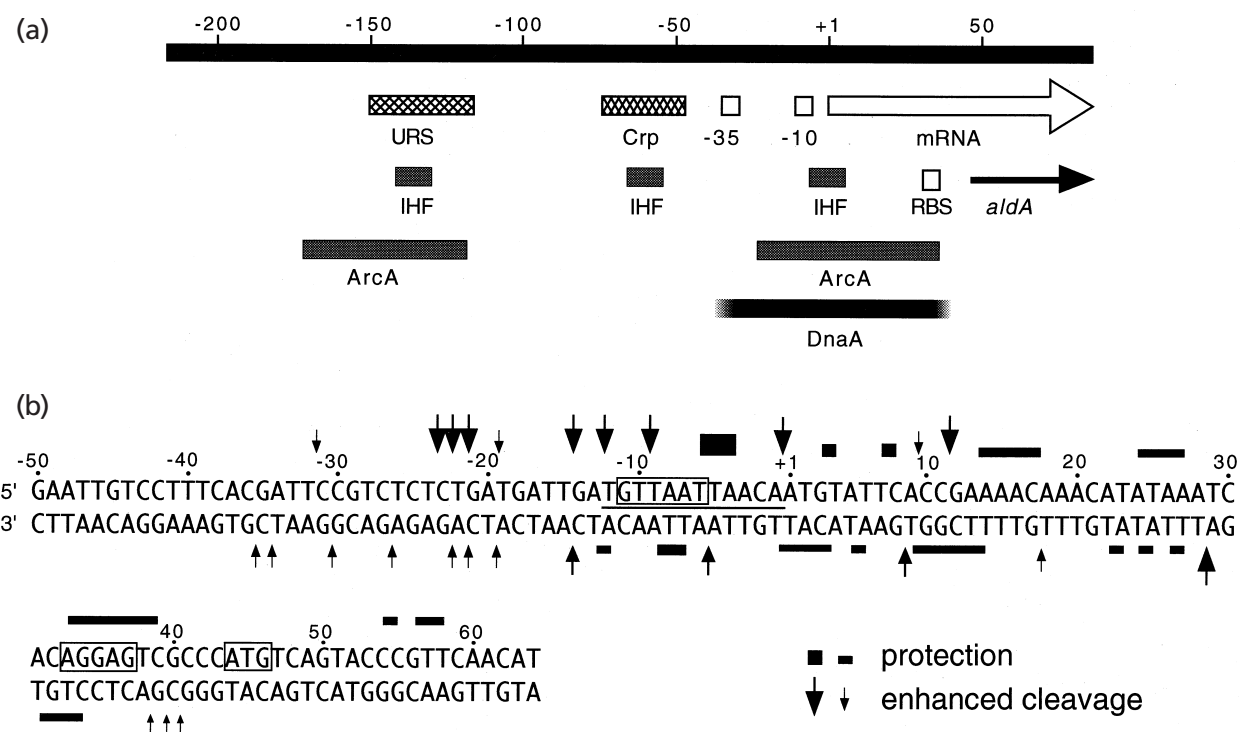

Fig. 4. (a) Representation of the aldA control region. Transcription of the aldA gene proceeds toward the right from position +1 . The promoter -35 and -10 boxes as well as the Shine-Dalgarno ribosome-binding sequence (RBS) are shown by unfilled boxes. Upstream regulatory sequence (URS) and binding sites of CAMP-Crp, IHF, ArcA-P and DnaA are also indicated. (b) Schematic representation of the DnaA protein footprint. Part of the Taql fragment, which extends from bp -184 to 77 , is shown. The -10 promoter sequence, ribosome-binding site and initiation codon are boxed and a $12 \mathrm{bp}$ palindrome is marked with a line between the two strands. Thickness of the solid blocks and size of the arrows reflect relative strength of protection and cleavage, respectively. Changes of the footprinting pattern appear at lower DnaA concentrations at sites of thick blocks and large arrows.

Table 1. Negative control of aldA-lacZ fusion gene by DnaA protein

\begin{tabular}{|lll|}
\hline Strain* & IPTG & $\boldsymbol{\beta}$-Galactosidase $(\mathbf{U})$ \\
\hline CSH50 & - & $0 \cdot 1 \pm 0 \cdot 06$ \\
CSH50(pFCmLZ1) & - & $0 \cdot 1 \pm 0 \cdot 04$ \\
CSH50(pFAL1) & - & $4 \cdot 0 \pm 0 \cdot 2$ \\
CSH50(pFAL1, pROA199) & - & $3 \cdot 4 \pm 0 \cdot 3$ \\
& + & $3 \cdot 5 \pm 0 \cdot 4$ \\
CSH50(pFAL1, pROA200) & - & $3 \cdot 3 \pm 0 \cdot 3$ \\
& + & $1 \cdot 0 \pm 0 \cdot 2$ \\
CSH50(pFAL1, pROAKK1) & - & $4 \cdot 2 \pm 0 \cdot 3$ \\
CSH50(pFAL1, pROAKK-EX) & - & $8 \cdot 6 \pm 0 \cdot 1$ \\
\hline
\end{tabular}

* See Methods and text for descriptions of plasmids.

galactosidase in lacZ cells carrying this plasmid (pFAL1) was dependent on the insert fragment, inasmuch as the control strain with a plasmid that did not carry this fragment ( $\mathrm{pFCmLZ1)}$ had only a background level of the $\beta$-galactosidase activity (Table 1 ). Induction of DnaA from pROA200 by the addition of IPTG resulted in repression of the $\beta$-galactosidase activity. The level of DnaA induction by this plasmid was about 10 -fold as measured by an immunoblotting experiment (data not shown). The effect of the control plasmid pROA199 was negligible in either the presence or absence of IPTG. In contrast, pROAKK-EX, which titrates a large amount of DnaA molecules to the datA locus on the plasmid (Kitagawa et al., 1998), derepressed the $\beta$-galactosidase activity, as has been observed on other DnaA-regulated genes. The control strain carrying the vector pROAKK1 instead of pROAKK-EX did not affect the $\beta$ galactosidase activity. These results suggest that DnaA negatively regulates the ald $A$ gene expression.

The minimal sequence required for efficient DnaA binding is not known but, supporting the footprinting data, similar results were obtained when the upstream TaqI-XmnI fragment $(-184$ to -59$)$ was removed from pFAL1 (data not shown).

\section{DISCUSSION}

DnaA protein usually recognizes a $9 \mathrm{bp}$ sequence $(\mathrm{DnaA}$ box), TTAT(C/A)CA(C/A)A (Fuller et al., 1984) or TT(A/T)TNCACA (Schaper \& Messer, 1995). Weak interaction to sites deviating from this sequence has been observed (Fuller et al., 1984; Yung \& Kornberg, 1989; Schaefer \& Messer, 1991) and a relaxed DnaA box sequence proposed (Schaefer \& Messer, 1991). The DnaA-DNA interaction seems to be strengthened when two or more weak binding sites are present on the same DNA fragment (Konopa et al., 1999; authors' unpublished observation). In a recent study, a 6-mer sequence, AGATCT, has been shown to interact with ATP-bound DnaA when a canonical DnaA box is present in close proximity (Speck et al., 1999). The aldA 
regulatory region appears to be distinct from these examples in that the interaction is relatively strong and stable, despite the absence of any consensus sequence. A characteristic of the ald $A$ promoter region is the presence of AT clusters between positions -10 and 30 . We assume that these AT clusters serve as the target sites of DnaA, inasmuch as major protection occurs at these sites. A palindromic sequence of $12 \mathrm{bp}$ extends from the -10 promoter sequence to the first protection site, but its significance is unknown. The 368 bp pBR322 fragment which has a weak binding activity, despite the lack of strong homologies to the DnaA box, also has several AT clusters (Fuller et al., 1984). DnaA-binding activity of this fragment, however, is very weak as compared to the origin fragment of pBR322 carrying two DnaA boxes.

Although several discrete bands appeared in a gel mobility shift assay, we could not attribute the mobility shift to the binding of DnaA to a new specific site. It seems that DnaA bound first at a site between the transcription start site and the -10 sequence on the upper strand triggered the cooperative binding upon increase of the number of bound molecules. Both protection and enhancement sites repeated at roughly $10 \mathrm{bp}$ intervals and finally covered about $100 \mathrm{bp}$ of sequence. A similar cooperative binding has been observed on a fragment containing a single canonical DnaA box (Fuller et al., 1984). In this case, 20-30 DnaA monomers covering about $100 \mathrm{bp}$ have been visualized by electron microscopy, but a gel mobility shift experiment has not been done and structures of intermediate complexes are unknown. The stoichiometry of binding is not certain in our study, because it appears that the binding is not saturated even at the highest amount of the input DnaA protein (Fig. 2).

DnaA-binding sites on the chromosome may function to control the frequency of initiation of DNA replication by titrating the initiator. The only example known at present to have such a function is the datA locus, which titrates an extremely large amount of DnaA molecules (Kitagawa et al., 1998). Deletion of this locus causes overinitiation of DNA replication. The aldA regulatory region, however, may not have such physiological significance, inasmuch as growth of cells carrying pRP270T is not impaired. High-copy-number plasmids carrying datA severely retard cell growth rate by lowering the free DnaA concentration (Kitagawa et al., 1998). In addition, gene dosage of the aldA region is lowest in growing cells due to its location on the genome (32 $\mathrm{min}$ ) close to the ter site.

Negative control of aldA gene expression by DnaA was suggested from the derepression assay (Table 1). It should be noted, however, that such an effect was observed only in a minimal medium in the presence of glucose. Under these conditions, expression of ald $A$ is limited (Limon et al., 1997). In M9 medium containing rhamnose in place of glucose and supplemented with Casamino acids, or in L-broth, where expression of the gene is induced, neither increase nor decrease of cellular
DnaA concentration affected the level of $\beta$-galactosidase activity (data not shown). Formation of a specific transcription initiation complex or efficient transcription initiation may block the binding of DnaA to the regulatory region.

\section{ACKNOWLEDGEMENTS}

This work was supported by Grants-in-Aid for Scientific Research from the Ministry of Education, Science, Sports and Culture of Japan.

\section{REFERENCES}

Fuller, R. S., Funnell, B. E. \& Kornberg, A. (1984). The DnaA protein complex with the E. coli chromosomal replication origin (oriC) and other DNA sites. Cell 38, 889-900.

Hansen, F. G., Koefoed, S., Sørensen, L. \& Atlung, T. (1987). Titration of DnaA protein by oriC DnaA-boxes increases dnaA gene expression in Escherichia coli. EMBO J 6, 255-258.

Hidalgo, E., Chen, Y.-M., Lin, E. C. C. \& Aguilar, J. (1991). Molecular cloning and DNA sequencing of the Escherichia coli K12 ald gene encoding aldehyde dehydrogenase. J Bacteriol 173, 6118-6123.

Kitagawa, R., Mitsuki, H., Okazaki, T. \& Ogawa, T. (1996). A novel DnaA protein-binding site at $94.7 \mathrm{~min}$ on the Escherichia coli chromosome. Mol Microbiol 19, 1137-1147.

Kitagawa, R., Ozaki, T., Moriya, S. \& Ogawa, T. (1998). Negative control of replication initiation by a novel chromosomal locus exhibiting exceptional affinity for Escherichia coli DnaA protein. Genes Dev 12, 3032-3043.

Kohara, Y., Akiyama, K. \& Isono, K. (1987). The physical map of the whole E. coli chromosome: application of a new strategy for rapid analysis and sorting of a large genomic library. Cell 50, 495-508.

Konopa, G., Szalewska-Palasz, A., Schmidt, A., Srutkowska, S., Messer, W. \& Wegrzyn, G. (1999). The presence of two DnaAbinding sequences is required for an efficient interaction of the Escherichia coli DnaA protein with each particular weak DnaA box region. FEMS Microbiol Lett 174, 25-31.

Kornberg, A. \& Baker, T. A. (1992). DNA Replication, 2nd edn. New York: Freeman.

Limon, A., Hidalgo, E. \& Aguilar, J. (1997). The aldA gene of Escherichia coli is under the control of at least three transcriptional regulators. Microbiology 143, 2085-2095.

Messer, W. \& Weigel, C. (1997). DnaA initiator - also a transcription factor. Mol Microbiol 24, 1-6.

Miller, J. H. (1972). Experiments in Molecular Genetics. Cold Spring Harbor, NY: Cold Spring Harbor Laboratory.

Parada, C. A. \& Marians, K. J. (1991). Mechanism of DnaA protein-dependent pBR322 DNA replication. DnaA proteinmediated trans-strand loading of the DnaB protein at the origin of pBR322 DNA. J Biol Chem 266, 18895-18906.

Pellicer, M. T., Lynch, A. S., De Wulf, P., Boyd, D., Aguilar, J. \& Lin, E. C. C. (1999). A mutational study of the ArcA-P binding sequences in the aldA promoter of Escherichia coli. Mol Gen Genet 261, 170-176.

Quintilla, F. X., Baldoma, L., Badia, J. \& Aguilar, J. (1991). Aldehyde dehydrogenase induction by glutamate in Escherichia coli. Role of 2-oxoglutarate. Eur J Biochem 202, 1321-1325.

Schaefer, C. \& Messer, W. (1991). DnaA protein/DNA inter- 
action. Modulation of the recognition sequence. Mol Gen Genet 226, 34-40.

Schaper, S. \& Messer, W. (1995). Interaction of the initiator protein DnaA of Escherichia coli with its DnaA target. J Biol Chem 270, 17622-17626.

Speck, C., Weigel, C. \& Messer, W. (1999). ATP- and ADP-DnaA protein, a molecular switch in gene regulation. EMBO J 18, 6169-6176.

Straney, D. C., Straney, S. B. \& Crothers, D. M. (1989). Synergy between Escherichia coli CAP protein and RNA polymerase in the lac promoter open complex. J Mol Biol 206, 41-57.

Yung, B. Y. \& Kornberg, A. (1989). The DnaA initiator protein binds separate domains in the replication origin of Escherichia coli. J Biol Chem 264, 6146-6150.

Received 7 August 2000; revised 13 September 2000; accepted 15 September 2000. 